\title{
Benefícios da intervenção fonoaudiológica em call center: revisão de literatura
}

\author{
Benefits of speech therapy intervention in a call center: literature review \\ Beneficios de la intervención de logopedia en un centro de llamadas: revisión de la literatura
}

Recebido: 12/11/2021 | Revisado: 20/11/2021 | Aceito: 23/11/2021 | Publicado: 26/11/2021

\author{
Vanusa Campos de Melo \\ ORCID: https://orcid.org/0000-0002-9402-5422 \\ Faculdade de Ensino Superior do Piauí, Brasil \\ E-mail: v.camposdemelo@gmail.com \\ Gleiser Wesley Pires Oliveira \\ ORCID: https://orcid.org/0000-0003-3498-1823 \\ Faculdade de Ensino Superior do Piaú, Brasil \\ E-mail:Gleyserwesley@grupomagister.com.br \\ Ruth Raquel Soares de Farias \\ ORCID: https://orcid.org/0000-0002-0988-0900 \\ Faculdade de Ensino Superior do Piauí, Brasil \\ E-mail: ruthraquelsf@gmail.com
}

\begin{abstract}
Resumo
O teleatendimento vem conseguindo um amplo espaço no Brasil por meio do advento dos call centers, responsável pela terceirização dos setores empresariais gerando uma mudança na interação com os clientes por meio de telefones. Assim, a voz muito usada nesse tipo de trabalho devendo ser clara, pois a partir do momento em que sua produção ocorre caracterizada por uma intensidade e uma projeção de modo adequado, ocasiona um desempenho vocal adequado para os profissionais que atuam na área do telemarketing. O objetivo da pesquisa consiste em analisar os principais benefícios da intervenção fonoaudiológica em call Center. Para a fundamentação da pesquisa foi necessário realizar uma revisão bibliográfica do tipo integrativa, analisando teorias sobre a forma correta da utilização de profissionais que trabalham em call Center. Para a seleção das fontes de pesquisa recorreu-se as bases de dados da Scielo, da Pubmed e Capes, utilizando fontes produzidas entre os anos de 2012 a 2021, sendo a busca realizada entre os meses de agosto e outubro do ano de 2021. Por meio da pesquisa foi possível evidenciar vários benefícios da fonoaudiologia para a saúde dos profissionais de call Center, ressaltando-se melhores formas de utilização da voz, evitando, assim, a tosse, a rouquidão, dentre outros problemas.
\end{abstract}

Palavras-chave: Telemarketing; Saúde; Voz.

\begin{abstract}
Teleservice has gained ample space in Brazil through the advent of call centers, responsible for outsourcing the business sectors, generating a change in the interaction with customers through telephones. Thus, the voice often used in this type of work must be clear, as from the moment its production is characterized by an adequate intensity and projection, it causes an adequate vocal performance for professionals working in the telemarketing area. The objective of the research is to analyze the main benefits of speech therapy intervention in a call center. To substantiate the research, it was necessary to carry out an integrative literature review, analyzing theories about the correct use of professionals working in call centers. For the selection of research sources, the databases of Scielo, Pubmed and Capes were used, using sources produced between the years 2012 to 2021, with the search carried out between the months of August and October of the year 2021. By Through the research, it was possible to evidence several benefits of speech therapy for the health of call center professionals, emphasizing better ways of using the voice, thus avoiding coughing, hoarseness, among other problems.
\end{abstract}

Keywords: Telemarketing; Health; Voice.

\section{Resumen}

Teleservice ha ganado un amplio espacio en Brasil a través del advenimiento de los call center, responsables de la tercerización de los sectores comerciales, generando un cambio en la interacción con los clientes a través de los teléfonos. Así, la voz que se utiliza con frecuencia en este tipo de trabajos debe ser clara, ya que desde el momento en que su producción se caracteriza por una adecuada intensidad y proyección, provoca una adecuada interpretación vocal para los profesionales que laboran en el área de telemarketing. El objetivo de la investigación es analizar los principales beneficios de la intervención logopédica en un call center. Para fundamentar la investigación fue necesario realizar una revisión integradora de la literatura, analizando teorías sobre el uso correcto de los profesionales que trabajan en los call centers. Para la selección de las fuentes de investigación se utilizaron las bases de datos de Scielo, Pubmed y Capes, utilizando fuentes producidas entre los años 2012 a 2021, con la búsqueda realizada entre los meses 
de agosto y octubre del año 2021. Por A través de la investigación, se pudo evidenciar varios beneficios de la logopedia para la salud de los profesionales de call center, enfatizando mejores formas de usar la voz, evitando así tos, ronquera, entre otros problemas.

Palabras clave: Telemarketing; Salud; Voz.

\section{Introdução}

O teleatendimento passou a lograr um amplo espaço no território brasileiro, especialmente, durante a década de 1980 por meio do advento dos call centers, o qual foi responsável por uma espécie de terceirização dos setores empresariais responsáveis, principalmente, pelas vendas do estabelecimento empresarial gerando uma mudança no que se refere a interação de forma direta nos balcões pelo contato através de telefones (Oliveira, 2018).

A voz é amplamente usada como um verdadeiro instrumento para o trabalho e, consequentemente, para ascensão nas mais diversas profissões existentes na sociedade vigente, como por exemplo, no serviço de call center o qual é considerado bastante moderno, tendendo a se ampliar de forma expressiva. Nessa atividade laboral a voz é o principal instrumento para buscar o êxito nos diversos objetivos, ressaltando-se, especialmente as finalidades, tanto assistenciais, como atividades comerciais (Garcia, 2020).

O crescimento dessa espécie de serviço traz a necessidade de um contínuo aperfeiçoamento e a capacitação dos operadores responsáveis pelo teleatendimento, devido ao amplo papel desempenhado na interação comunicativa entre a instituição empresarial e os seus respectivos clientes, exigindo-se, assim, desse funcionário um adequado controle emocional em prol de atender as principais demandas pessoais que em muitos casos são bastante difíceis, envolvendo débitos, má prestação de serviços, dentre outros casos (Pontes, 2018).

Salienta-se que a voz é continuamente usada nos serviços de call center e por essa razão deve ser dotada de precisão e clareza, pois a partir do momento em que sua produção ocorre caracterizada por uma intensidade e uma projeção de modo adequado, ocasiona um desempenho vocal profícuo para os profissionais que atuam na área do telemarketing (Salzstein, 2018).

O objetivo da presente pesquisa consiste em analisar a intervenção da fonoaudiologia para os profissionais que atuam na área laboral do Call Center. Dentre os objetivos específicos, ressaltam-se: demonstrar como a voz é utilizada nos serviços de Call Center; identificar as principais queixas fonoaudiológicas de profissionais de telemarketing; verificar as principais enfermidades ocasionadas pelo desenvolvimento de atividades no Call Center;

A problemática da pesquisa está fundada no seguinte questionamento: como os profissionais de Fonoaudiologia podem contribuir para um melhor desempenho dos profissionais que atuam em call Center?

Justifica-se a escolha do tema em razão da necessidade de uma orientação continua aos trabalhadores que atuam em call center em prol da melhor utilização de suas vozes, sem que usem o principal instrumento de trabalho de forma indevida, trazendo como consequência o surgimento dos mais diversos tipos de disfonias funcionais, ocasionando, consequentemente, lesões secundárias, principalmente, por trauma da mucosa das pregas vocais, sendo bastante comum os profissionais de call Center procurarem assistência médica devido a queixas relacionadas com a questão de ressecamento, de cansaço ao falar, de intenso esforço, tosse contínua, rouquidão, pigarro, falhas na voz, sensação de ardência e de corpo estranho na região da garganta (Santos, 2016).

Vários desses sintomas encontram-se diretamente associados com a questão da má utilização e do abuso da voz, além das condições físicas inadequadas presente no ambiente laboral, como ar condicionado sujo, muitos ruídos ambientais, necessitando de uma maior intensidade da voz, dentre outros (Sanchez, 2017).

Dessa forma a pesquisa é bastante pertinente, podendo servir como mais uma fonte de pesquisa para atuais e futuros acadêmicos do curso de fonoaudiologia, em especial, aqueles, que procuram entender as consequências da má utilização da voz humana. 


\section{Referencial Teórico}

\subsection{Call Center}

O teleatendimento no Brasil se desenvolveu durante a década de 1980 por meio do surgimento dos call centers, sendo uma terceirização das áreas responsáveis pelas vendas nos mais diversos estabelecimentos empresariais gerando, dessa forma, uma substituição do contato direto nos balcões das empresas pelo contato através do uso de telefones. No ano de 1987 ocorreu no Território da República Federativa do Brasil a privatização do setor de telecomunicação, originando a Associação Brasileira de Telesserviços (ABT).

Já no ano de 1996 essa associação foi responsável pela elaboração do código de conduta e de princípios éticos para o telemarketing com o escopo de cumprir o que já se encontrava previamente estava estabelecido no Código de Defesa do Consumidor (CDC). Salienta-se que o telemarketing era conhecido como uma área responsável pela realização de vendas por meio do telefone, atualmente esse setor detém muitas outras áreas como, por exemplo o SAC, as pesquisas de mercado, além da cobrança de dívidas. Em suma, a atividade realizada em telemarketings é a de call center (PROBARE, 2018).

O call center pode ser caracterizado como uma ferramenta, capaz DE desenvolver as empresas em um mercado altamente competitivo, isto é, a partir do momento em que ocorre o devido investimento na área de telemarketing o fornecedor proporciona uma maior comodidade aos seus respectivos consumidores, e consequentemente, um atendimento adequado, sem que haja a necessidade da ida dos clientes até o estabelecimento empresarial, principalmente durante um período acometido por uma pandemia, como é o caso da Covid 19, que infectou e foi responsável direto por muitos óbito em todo o mundo (Garcia, 2020).

O operador de telemarketing acaba contribuindo para a construção da boa imagem da empresa e sem o auxílio da comunicação facial e corporal, depende exclusivamente da voz para cativar o cliente e atingir as metas propostas, portanto os exercícios vocais e as técnicas vão contribuir na melhoria do teleatendimento sem prejudicar a saúde dos funcionários.

Desta forma, conforme Monteiro (2017) as principais características exigidas pelas instituições empresariais para os operadores de telemarketing, na atualidade, ressaltam-se:

- Voz sempre bem aquecida e sem rouquidão.

- $\quad$ Clareza na comunicação.

- Domínio do português correto.

- $\quad$ Autoestima, humor sempre equilibrado.

- $\quad$ Paciência

- Receptividade

- $\quad$ Atenção

Assim observa-se a grande importância dos profissionais de fonoaudiologia, pois por meio de suas habilidades pode evitar que os operadores de call Center possam possuir uma voz sem rouquidão causada pela contínua utilização nas atividades, além de clareza ao falar, por exemplo.

\subsubsection{Espécies}

Segundo Monteiro (2017, p.11)) no Brasil as instituições empresariais já atuam nas 12 (doze) principais áreas do telemarketing logrando grande êxito, conforme detalhado:

Venda ativa e receptiva: é uma das aplicações mais utilizadas pelos mais diversos ramos de atividades, também É conhecida como Televendas; 
Promoções: são realizadas por telefone para promover ou lançar produtos/serviços, com ou sem utilização de outras mídias;

Atendimento a reclamações: é uma das aplicações do telemarketing geralmente absorvida pelo SAC (Serviço de Atendimento ao Consumidor);

Apoio a vendas externas: esta área colabora com a equipe de vendas de campo realizando bons contatos através do agendamento de visitas. Desempenha também uma variedade de funções de apoio, tais como qualificação de leads, verificação de posição de crédito, controle de pedidos e de entregas, e outras;

Orientação e informação ao consumidor: área que também é absorvida pelo SAC;

Cobrança: área que necessita de treinamento para preparo da linguagem específica para e este fim e para os diversos casos;

Veiculação: normalmente é feita pela equipe de telemarketing associada a mídia, como forma de difundir, transmitir e propagar no mercado o produto ou serviço;

Assistência pós-venda: tem como objetivo avaliar o grau de satisfação do cliente com o produto adquirido, corrigir possíveis falhas e estreitar o relacionamento, conquistado a fidelidade do cliente.

Compras: O operador da área de compras necessita desenvolver habilidades específicas à função:

a) Conhecer profundamente o produto e das tendências do mercado;

b) ser criativo;

c) dominar técnicas de negociação.

Suporte a rede varejista: é conseguido através de:

d) Implantação de televendas para recepção dos produtos das lojas;

e) Serviço de assistência técnica para o varejo atender com qualidade e tempo real o consumidor.

Autorização de crédito contatos telefônicos realizados com empresas especializadas no campo de liberação de crédito.

Pesquisa: utilizada para os mais diversos fins, por exemplo, pesquisa política ou para verificar a aceitação de determinados produtos no mercado.

Conforme observado o Call Center ou telemarketing não pode estar associado somente a vendas por telefone, mais envolve uma série de atividades que corroboram significativamente na vida e na comodidade de um número considerável de pessoas no Brasil e no mundo.

Assim, em todos os tipos de telesserviço há uma aplicação integrada das tecnologias de telecomunicações e de processamento de dados. Independentemente da modalidade de telesserviço, o teleoperador tem contato com diversos agentes estressores, e trabalha sob considerável pressão. Este profissional deve desempenhar sua função de maneira competente, obedecer a mecanismos de controles rigorosos e atingir metas determinadas pela empresa (Amorim, 2011).

\section{2 a intervenção fonoaudiológica em trabalhadores de call center}

Com relação às intervenções realizadas por estes profissionais, Oliveira (et. al. 2018) consideram que o ABA (Applied Behavior Analysis) e PECS (Picture Exchange Communication System) juntos contribuem para uma melhoria significativa da comunicação. O fonoaudiólogo irá trabalhar a estimulação das habilidades de comunicação verbal e não verbal e eventuais distúrbios de aprendizagem.

Mesmo sendo de grande importância, a atuação fonoaudiológica nas mais diversas centrais de Call Center e telemarketing iniciou-se somente por volta de 12 anos atrás, no entanto, eram executados somente atividades esporadicamente de forma isolada.

O operador de telemarketing, pode ser considerado com um verdadeiro profissional da voz dotado de uma enorme demanda vocal-operacional, sendo colocado em uma realidade laboral caracterizada pela busca contínua de metas e e de atendimentos com períodos de tempo que devem ser seguidos prontamente (salzstein, 2018).

Essa exigência pelos recursos vocais dos trabalhadores de Call Center causa a origem de muitas alterações capazes de comprometer maleficamente a a voz, prejudicando ou impedindo o exercício das funções. Assim, os operadores de call center demonstram uma prevalência ampla de problemas vocais, diretamente relacionados aos fatores de risco modificáveis. Desse modo há a necessidade precípua da redução da demanda vocal e transformações em fatores específicos, como o hábito de fumar, a utilização excessiva de fármacos, sedentarismos, dentre outros (Penteado, 2019). 
Por meio da intervenção fonoaudiológica é possível evidenciar uma ampliação no que se refere a percepção de profissionais que atuam em call center, quanto às suas vozes, em razão de um treinamento auditivo com a utilização de gravação de áudio e de vídeo realizadas durantes oficinas realizadas por fonoaudiólogos e posteriormente exibidas ao grupo para uma maior estimulação da autoavaliação vocal, sendo a conscientização da voz um excelente instrumento dotado de suma importância para uma comunicação considerada adequada no ambiente laboral. A presença contínua dos fonoaudiólogos em Call Center é necessária porque a voz é o principal instrumento de trabalho devendo ser sempre um foco de preocupação das instituições empresariais. (Aronson, 2017).

Assim os fonoaudiólogos devem participar desde o momento da criação de um call center, como por exemplo no momento em que serão escolhidos os teleoperadores, estando presentes no treinamento, no monitoramento das equipes, na questão do aperfeiçoamento da comunicação, assim como, também, em questões atinentes no que se refere a prevenção de doenças ocupacionais (Santos, 2016).

Amorim (2011, p.71) discorre sobre a importância do profissional de Fonoaudiologia para os profissionais que atuam em call Center:

Considerando-se a importância desse profissional para o cenário socioeconômico do país, pode-se afirmar que qualquer alteração vocal ao longo de sua jornada de trabalho poderá comprometer significativamente seu desempenho profissional. Desta forma, é extremamente importante que haja uma assessoria fonoaudiológica para realizar intervenções vocais junto a essa população. Por conseguinte, é necessário não apenas compreender as particularidades desta categoria profissional, mas, também, as características vocais comuns ao grupo. Nesse sentido, o fonoaudiólogo é o profissional que exerce papel crucial junto aos teleoperadores, avaliando os parâmetros perceptivo-auditivos e as medidas acústicas da voz, no início e ao término da jornada de trabalho. Estes dados possibilitarão a avaliação e a programação de medidas preventivas eficientes para os problemas vocais enfrentados por teleoperadores. Diante da importância desta categoria profissional faz-se necessário o desenvolvimento de estudos para melhor compreensão das particularidades destes profissionais. Os resultados obtidos possibilitarão que fatores que dificultam a comunicação sejam eliminados ou atenuados, por de programas de treinamento vocal específicos às necessidades dos teleoperadores. Qualquer alteração vocal ou desequilíbrio na utilização dos recursos de comunicação poderá comprometer o desempenho profissional dos teleoperadores.

Nos dias atuais para que um profissional possa atuar em um trabalho de call center há a necessidade de focar não somente na questão da voz, mas também na fala, na linguagem e na audição buscando prevenir alterações vocais, em prol de uma contínua promoção de saúde e no aprimoramento da habilidade comunicativa proporcionando, dessa forma, a qualidade do atendimento (Costa, 2020).

No que se relaciona com a atuação do teleatendimento os profissionais da Fonoaudiologia podem contribuir significativamente para a saúde dos operadores, além de colaborarem diretamente com os mais diversos resultados almejados pela instituição empresarial por meio da identificação de falhas na comunicação, propiciando, desse modo, o seu maior aprimoramento (Pontes, 2018).

\section{Metodologia da Pesquisa}

No que se refere a metodologia a presente pesquisa caracteriza-se como uma revisão bibliográfica integrativa, por meio da análise de vários estudos na literatura internacional e nacional sobre a importância da intervenção fonoaudiológica na qualidade de vida e de desenvolvimento profissional de profissionais de call Center.

Com o objetivo de lograr um maior êxito na busca das fontes de pesquisa houve a seleção dos seguintes descritores em saúde (decs), ressaltando-se: call center, fonoaudiologia, telemarketing, voz. 
Dentre os critérios de inclusão somente foram incluídos na pesquisa artigos que tratassem somente da intervenção da fonoaudiológica em call center, sendo excluídas as fontes que apresentavam a importância a atuação de fonoaudiólogos em outras temáticas

O segundo critério de inclusão pautou-se no lapso temporal da elaboração dos artigos, sendo incluídas somente fontes cuja publicação tenha ocorrida entre os anos de 2011 a 2021, sendo excluídas fontes de pesquisa fora desse lapso temporal.

Após o critério de inclusão e de exclusão foram encontrados 28 artigos, no entanto somente 5 artigos estavam relacionados com a intervenção fonoaudiológica em call center, sendo 1 encontrado na base de dados da Pubmed, 3 na base de dados Scielo e 1 no portal de periódicos capes.

Assim, como um recurso metodológico, em prol de uma melhor compreensão das fontes que embasaram a pesquisa, houve a necessidade da elaboração da Figura 1, a qual está constituída dos artigos que foram utilizados, demonstrando quais bases de dados foram utilizadas e o quantitativo de artigos incluídos e excluídos na pesquisa.

Figura 1: Quantidade de artigos conforme a base de dados.

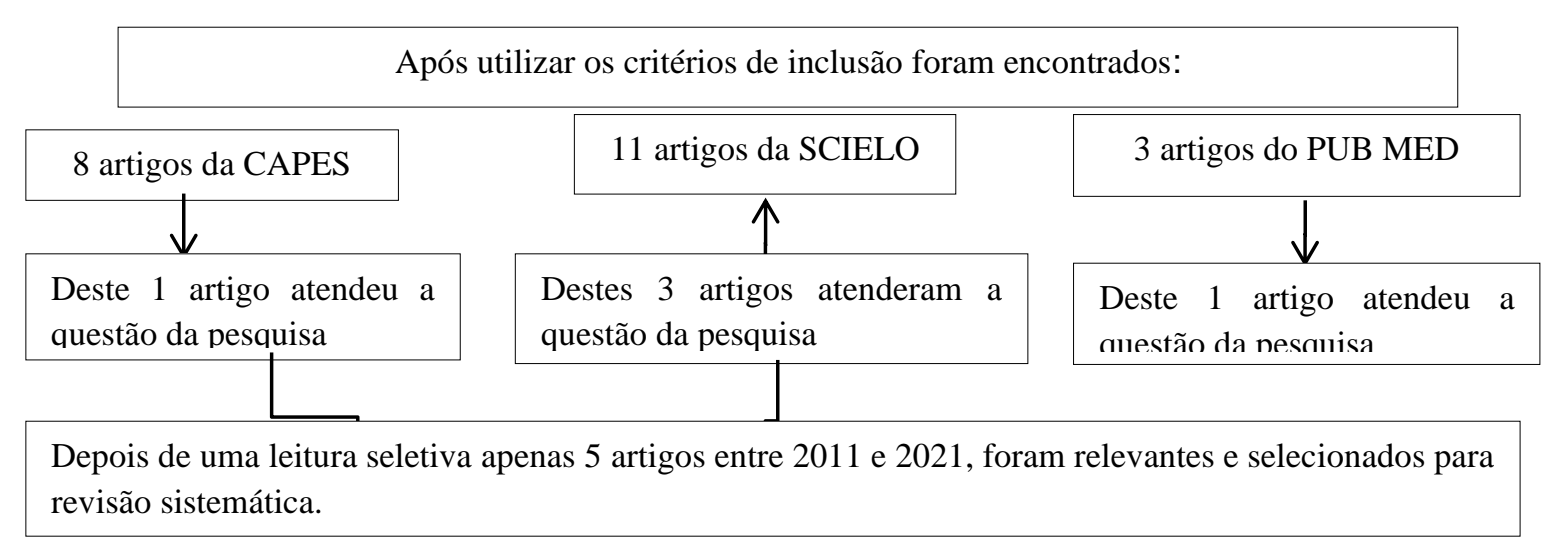

Fonte: Autores (2021).

Posteriormente a realização da análise dos artigos inseridos na presente pesquisa realizou-se a elaboração do quadro 1, o qual apresenta o autor, o título da pesquisa, a metodologia utilizada e os resultados que foram conseguidos com a intervenção da Fonoaudiologia nos trabalhadores que atuam em call center.

\section{Resultados e discussão}

O Quadro 1 discrimina, conforme a pesquisa bibliográfica integrativa, a importância da intervenção Fonoaudiológica em Trabalhadores que atuam nos ambientes laborais de call centers ou de telemarketinh. 
Quadro 1: Benefícios da intervenção da fonoaudiologia em call center.

\begin{tabular}{|c|c|c|c|}
\hline Autor/Título & Base de dados & Metodologia & Resultados \\
\hline $\begin{array}{ll}\text { Oliveira } & \text { S. } \\
(2021) & \\
\text { A voz no } \\
\text { telesserviço }\end{array}$ & SCIELO & 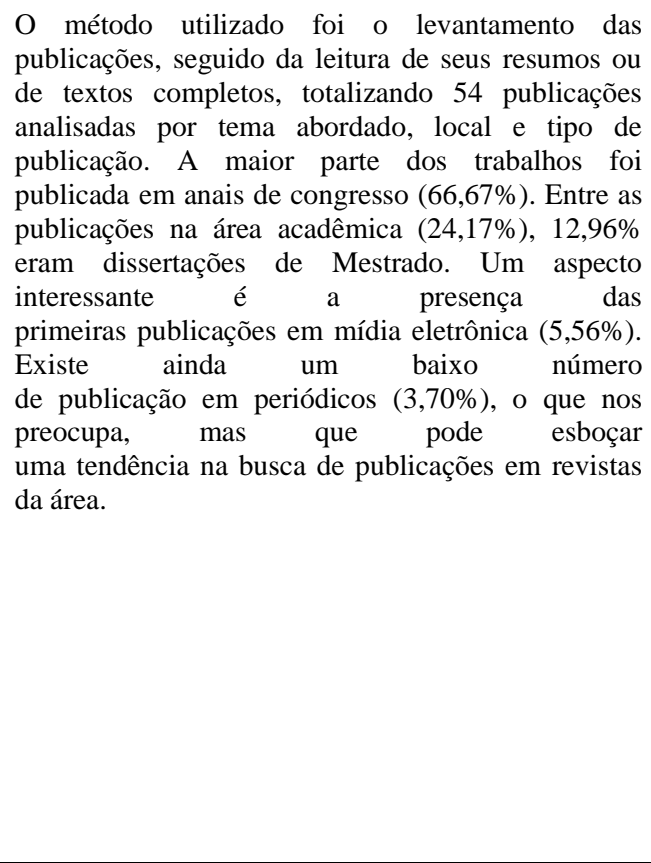 & 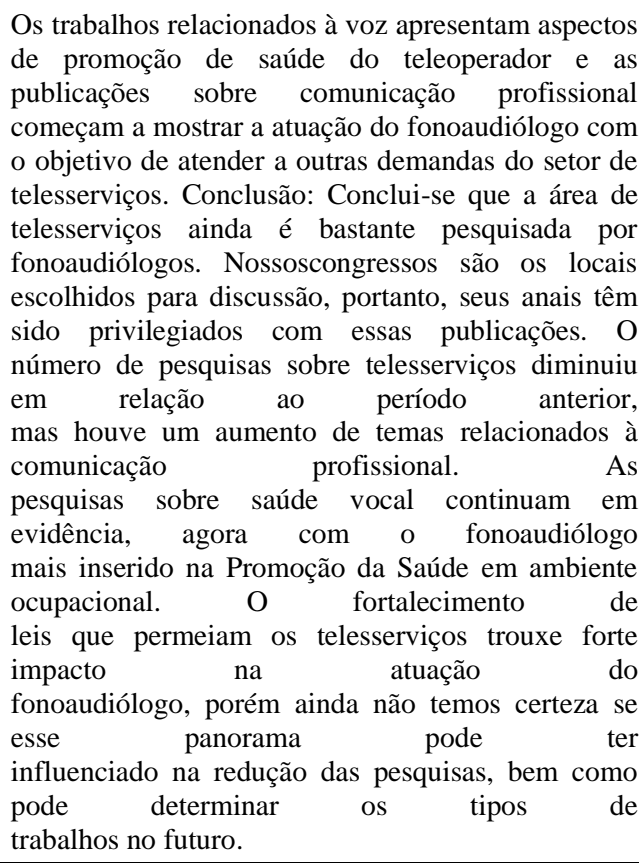 \\
\hline $\begin{array}{l}\text { Amorim G.O. } \\
(2011) \\
\text { Comportamento } \\
\text { vocal de } \\
\text { teleoperadores } \\
\text { pré e pós- } \\
\text { jornada de } \\
\text { trabalho }\end{array}$ & SCIELO & $\begin{array}{l}\text { Participaram } 55 \text { teleoperadores de uma empresa de } \\
\text { teleatendimento na cidade de Maceió (AL), sendo } 11 \\
\text { homens e } 44 \text { mulheres, com atuação no modo } \\
\text { receptivo. Inicialmente, foi aplicado um questionário } \\
\text { antes da jornada de trabalho para identificação das } \\
\text { queixas vocais. Em seguida foi feita gravação de } \\
\text { amostras vocais compostas por emissões sustentadas } \\
\text { e fala encadeada } 10 \text { minutos antes e } 10 \text { minutos após } \\
\text { a jornada de trabalho para serem posteriormente } \\
\text { avaliadas. Foram realizadas avaliações perceptivo- } \\
\text { auditiva e acústica da voz }\end{array}$ & 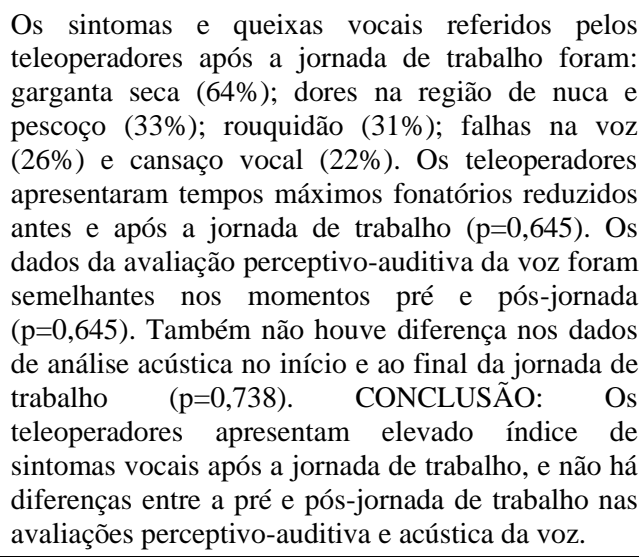 \\
\hline 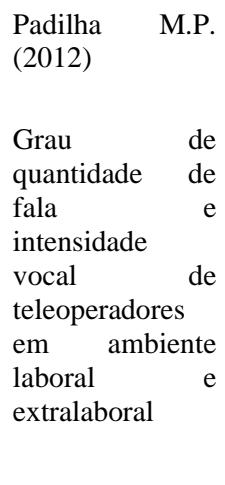 & CAPES & $\begin{array}{l}\text { Participaram } 299 \text { teleoperadores ativos e receptivos, } \\
\text { de ambos os gêneros, com média de idade de } 27,1 \\
\text { anos. Foi aplicado o "Teste de grau de quantidade de } \\
\text { fala e grau de intensidade vocal" em duas situações } \\
\text { de comunicação: voz laboral e extralaboral, além da } \\
\text { realização de autoavaliação vocal e análise } \\
\text { perceptivo-auditiva. }\end{array}$ & $\begin{array}{l}\text { No setor de telesserviços há um maior número de } \\
\text { mulheres em relação ao número de homens, com } \\
\text { média de idade de } 27,1 \text { anos. Em relação ao gênero, } \\
\text { mulheres falam mais em ambiente laboral quando } \\
\text { comparadas aos homens. Ao comparar quantidade } \\
\text { de fala e intensidade de voz dentro e fora do } \\
\text { trabalho, é observado maior uso e intensidade vocal } \\
\text { no ambiente laboral. O teleoperador é um } \\
\text { profissional da voz que relata falar mais e falar mais } \\
\text { alto em situações de trabalho. Mulheres dessa } \\
\text { categoria profissional falam mais que homens em } \\
\text { qualquer uma das situações avaliadas. Não se } \\
\text { observou correlação entre quantidade de fala, } \\
\text { intensidade de voze autoavaliação da voz. }\end{array}$ \\
\hline $\begin{array}{l}\text { Monica F.S.S. } \\
\text { (2014) } \\
\text { Sintomas vocais } \\
\text { e absenteísmo } \\
\text { em } \\
\text { teleoperadores } \\
\text { sindicalizados }\end{array}$ & SCIELO & $\begin{array}{l}\text { Realizou-se um estudoepidemiológico de } \\
\text { cortetransversal, com caráter descritivo. Utilizou-se } \\
\text { uma amostra de conveniência composta por } 80 \\
\text { teleoperadores que buscaram atendimento no } \\
\text { Sindicato dos Tra-balhadores em Telecomunicações } \\
\text { da Bahia (SINTTEL-BA), no período de julho a } \\
\text { outubro de 2010. Foram incluídos operadores de } \\
\text { telemarketing ativo e receptivo, sem restrição de } \\
\text { faixa etária e de ambos os sexos. Os trabalhadores } \\
\text { procuram o sindicato para os serviços de } \\
\text { homologação da rescisão de contrato de trabalho, } \\
\text { atendimento médico ou jurídico e busca de }\end{array}$ & 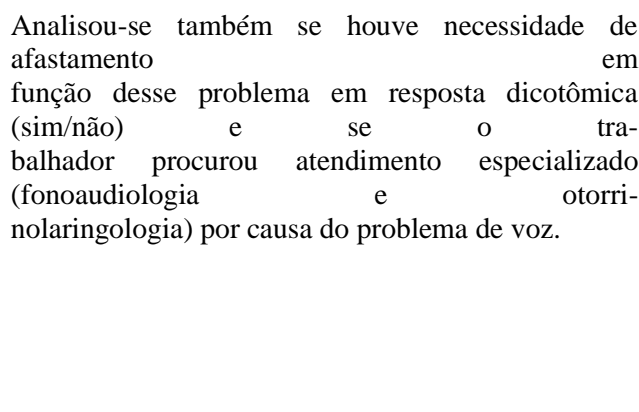 \\
\hline
\end{tabular}




\begin{tabular}{|c|c|c|c|}
\hline & & $\begin{array}{l}\text { informações. Cada teleoperador, que compareceu ao } \\
\text { sindicato e aceitou participar do estudo, foi } \\
\text { entrevistado. A coleta de dados foi realizada durante } \\
\text { o horário de funcionamento do sindicato nos turnos } \\
\text { da manhã e/ou tarde, de segunda a sexta-feira, em } \\
\text { dias alternados. Portanto, o critério de inclusão foi } \\
\text { ter procurado o sindicato e aceitar participar do } \\
\text { estudo. }\end{array}$ & \\
\hline $\begin{array}{l}\text { Diogo } \\
(2021) \\
\\
\text { A } \\
\text { Fonoaudiologia } \\
\text { auditiva e vocal } \\
\text { como fator } \\
\text { gerador de bem- } \\
\text { estar } \\
\begin{array}{ll}\text { ambiente no } \\
\text { trabalho }\end{array}\end{array}$ & PUBMED & $\begin{array}{l}\text { A pesquisa foi desenvolvida com base em orientação } \\
\text { de Ferreira (1999), sendo uma } \\
\text { revisão bibliográfica sobre o uso da voz como } \\
\text { instrumento de trabalho e pesquisa dos } \\
\text { descritores: Call Center, teleatendimento, } \\
\text { telemarketing e teleoperador utilizados em base de } \\
\text { dados MEDLINE (Medical Literature Analysis and } \\
\text { Retrievel System Online), BIREME } \\
\text { (Biblioteca do Ministério da Saúde - Centro } \\
\text { Especializado da OPAS - Organização Pan- } \\
\text { Americana da Saúde), SCIELO (Scientific } \\
\text { Electronic Library Online), LILACS (Centro } \\
\text { Latino-Americano e do Caribe de Informação em } \\
\text { Ciências da Saúde Área de Gestão do } \\
\text { Conhecimento), com o objetivo de compreender o } \\
\text { universo que se estava utilizando para o } \\
\text { exemplo de uso profissional da voz. }\end{array}$ & $\begin{array}{l}\text { Para um operador de telemarketing, cujo único } \\
\text { instrumento de trabalho é a comunicação oral, em } \\
\text { diálogo constante e imediato com o interlocutor, os } \\
\text { dois problemas mais citados (rouquidão e falha na } \\
\text { voz) figuram como obstáculos no desempenho de } \\
\text { suas funções para o alcance das metas e da qualidade } \\
\text { exigidas pela empresa }\end{array}$ \\
\hline
\end{tabular}

Fonte: Autores (2021).

A fonoaudiologia encontra-se cada vez mais voltada para a empresa expandir-se, trabalhando com o aprimoramento da comunicação oral de representantes de empresas na área comercial, nas diretorias e entre os executivos. Em telemarketing, o interesse dos fonoaudiólogos estão direcionados, principalmente, para o que se refere a comunicação oral, a utilização da voz de forma profissional e, também, questões atinentes com a saúde vocal dos operadores, desde os processos seletivos dos funcionários, nos programas em prol da capacitação e no aprimoramento dos operadores, desempenhando, dessa maneira, um papel de suma importância nas estratégias de boa comunicação às metas de qualidade de vida de profissionais e do desenvolvimento da instituições empresariais (Oliveira, 2021).

Considerando-se a importância dos profissionais que atuam em call center para o cenário socioeconômico do Brasil, qualquer alteração vocal decorrente de jornadas de trabalho pode comprometer seu desempenho profissional. assim, é importante que tenha uma assessoria fonoaudiológica em prol das realizações de intervenções vocais junto a essa população. Por conseguinte, há a necessidade não somente de compreender as particularidades desta categoria profissional, no entanto, também, as características vocais consideradas comuns ao grupo (Amorim, 2011).

Os fonoaudiólogos são importantes para o serviço de telemarketing e seus respectivos operadores em razão de possuírem habilidades para realizarem análises perceptivo-auditivas da voz no momento da avaliação, por meio da análise do grau de desvio vocal na fala espontânea, classificando-a em voz adaptada, desvio discreto, moderado ou extremo (PADILHA, 2012).

Dentre os principais problemas que acometem os profissionais do telemarketing ressaltam-se rouquidão, perda da voz, dor de garganta, inflamação de garganta e problemas múltiplos, sendo necessário o atendimento de saúde por meio de profissionais da área de saúde, ressaltando-se, médicos otorrinolaringologista, médicos do trabalho, fonoaudiólogo, dentre outros que compõem a equipe multidisciplinar (Mônica, 2014).

AS ameaças presentes no ambiente de trabalho de operadores de telemarketing necessitam de cuidados com a audição, como a utilização de forma não adequada dos headsets, pouca hidratação oral, higienização vocal, gerando as principais doenças ocupacionais dos operadores de telemarketing, necessitando de intervenção fonoaudiológica na busca da promoção da melhoria da saúde vocal e auditiva dos operadores. Entendemos que a orientação quanto à sensibilização e aos cuidados 
básicos para se ter uma voz adequada para o uso profissional, deve ser difundida entre empregadores que estão atentos ao fato de que a voz do teleoperador representa a empresa; por esta razão, um trabalho realizado por um fonoaudiólogo em muito contribuirá para as melhores condições de qualidade de vida de seus empregados e consequentemente de maior produtividade nos cumprimentos de suas metas (Diogo, 2021).

\section{Considerações Finais}

Evidencia-se por meio da presente pesquisa que os profissionais de Fonoaudiologia são de suma importância para o serviço relacionado com o Call Center. Dentre os principais benefícios, ressaltam-se a escolha dos perfis vocais considerados mais adequados para o tipo de estabelecimento empresarial, além de atendimentos realizados de forma individual aos operadores, proporcionando treinamentos específicos objetivando a comunicação e a saúde da voz;

Os fonoaudiólogos atuando conjuntamente com equipes multidisciplinares podem trazer vantagens competitivas de se ter um acompanhamento fonoaudiológico no estabelecimento da empresa, havendo a minimização de absenteísmo associados a a problemas vocais, principalmente em razão da redução de desvio de função devido patologias vocais adquiridas em razão da utilização contínua da voz sem os devidos cuidados na execução das atividades laborais.

Enfim, há também dentre os benefícios da atuação dos fonoaudiólogos a questão relacionada com a redução de tunover ocasionado por alterações vocais, além da diminuição de atestados médicos (vocal)e havendo a expressão da mensagem ao cliente de modo objetivo e claro, diminuindo interferências comunicativas nas mensagem, alcançando com objetividade o propósito para o qual foi colocado na empresa.

Ressalta-se que a presente pesquisa pode ser mais uma fonte de pesquisa para profissionais da Fonoaudiologia que se interessem pela temática da intervenção fonoaudiológica nos ambientes laborais do Call Center, além de corroborar na fundamentação teórica de futuras pesquisas sobre o tema realizadas por atuais e futuros acadêmicos de Fonoaudiologia.

\section{Referências}

Amorim G. O. (2011). Comportamento vocal de teleoperadores pré e pós-jornada de trabalho. J Soc Bras Fonoaudiol.

Aronson D. B. (2017). Objective analysis of actors'voices: an initial report. J.Voice.

Constancio S. (2012). Dores corporais em teleoperadores e sua relação com o uso da voz em atividades laborais. Rev. soc. bras. fonoaudiol. 17 (4)

Costa H. (2020). Voz ativa: falando sobre o profissional da voz. Roca.

Diogo J. R. M. (2021). A fonoaudiologia auditiva e vocal como fator gerador de bem-estar no ambiente de trabalho. Faculdade Pitágoras, Fortaleza

Garcia R. A. S. Operadores de uma central de telemarketing: os múltiplos sentidos da voz. [tese/mestrado]. Pontifícia Universidade Católica- Mestrado em Linguagem

Girardi B. B (2017). Relação entre condições de trabalho e sintomas vocais em operadores de um call center modelo. Audiol., Commun. Res. 22 (0) • 2017 https://doi.org/10.1590/2317-6431-2016-1738.

Kootler, P., \& Keller, K. L. (2016). Administração de Marketing. (18a ed.), Pearson Prentice Hall.

Leite A. P. D. (2011). Relação entre dados ocupacionais, sintomas e avaliação vocal de operadores de telesserviços. Rev Soc Bras Fonoaudiol. 2011;16(1):596

Mônica, F. S. S. (2014). Sintomas vocais e absenteísmo em teleoperadores sindicalizados. In: Fernandes, R. C. P., Lima, M. A. G., \& Araújo, T. M., comps. Tópicos em saúde, ambiente e trabalho: um olhar ampliado EDUFBA, 2014, 181-208. https://doi.org/10.7476/9786556300122.0010.

Oliveira T. R. S. (2018). Intervenção fonoaudiólogica e autismo Rev. CEFAC. 6, 808-814

Oliveira I. B. 25 anos de cuidados com a voz profissional: avaliando ações. Rev CEFAC. 2018

Oliveira, S. (2021). A voz no telesserviço. Revista de Lingüística Aplicada e Estudos da Linguagem pela PUC-SP. https://docplayer.com.br/1192905-A-vozno-telesservico.html. 
Research, Society and Development, v. 10, n. 15, e570101523215, 2021

(CC BY 4.0) | ISSN 2525-3409 | DOI: http://dx.doi.org/10.33448/rsd-v10i15.23215

Padilha M. P. (2012). A análise perceptivo-auditiva da voz foi realizada pelo fonoaudiólogo da empresa, no momento da avaliação, por meio da análise do grau de desvio vocal na fala espontânea, classificando-a em voz adaptada, desvio discreto, moderado ou extremo. Rev. soc. bras. fonoaudiol. 17 (4).

Pamponet C. (2021). Fonoaudiologia na empresa: Atuação em Call Center. Fonoclim.Rev. CEFAC.23.

Penteado R. Z. A voz do professor: relações entre trabalho, saúde e qualidade de vida. Rev. Bras. Saúde Ocup 2019.

PROBARE. Programa Brasileiro de Auto-Regulamentação. (2018). http://probare.org.br/.

Pontes P. (2018). Avaliação da voz. In: Behlau M. Voz: o livro do especialista. Revinter.

Rechemberg, L. (2015). Impacto da atividade laboral de teleatendimento em sintomas e queixas vocais: estudo analítico. J. Soc. Bras. Fonoaudiol. 23 (4)

Salzstein, R. B. W. (2018). Operador de telemarketing: relações entre trabalho e queixas vocais. In: Alloza, R. G., \& Salzstein, R. B. W. Fonoaudiologia na empresa: atuação em call center. Revinter; 55 -82.

Santos, I. R. Possibilidades de assessoria fonoaudiológica em centrais de telemarketing. CEFAC - Pós-graduação em Saúde e Educação. 